\title{
STRATEGIES FOR MAINTAINING QUALITY IN DISTANCE HIGHER EDUCATION
}

\author{
Dr. Sufiana Khatoon MALIK \\ Assistant Professor \\ Education Department \\ National University of Modern Languages (NUML), \\ Islamabad, PAKISTAN
}

\begin{abstract}
The current paper was produced with the purpose of suggesting strategies for bringing quality in distance education programs at higher education level. In recent times distance education is becoming an indispensable part of education system globally. Every institution is trying to offer their educational course through general as well through distance education means in order to make market for its programs. There is need to introduce quality distance education programs. It can be done through bringing quality in the curriculum and instruction of distance education programs, providing students quality support services, training faculty members in innovative methods of instruction of distance education, provision of technical support for promotion of research culture, adopting multiple ways of assessment of distance students, developing code of ethics for distance education faculty members and students, provision of quality infrastructure and technology, launching courses of distance education only through approval of national accreditation council for distance education (NACDE) and taking measures of check at every delivery system of distance education courses through quality control agencies.
\end{abstract}

Keywords: Strategies, quality distance education, curriculum, national accreditation council for distance education, delivery modes.

\section{INTRODUCTION}

Distance education is a system of education that in which instructor and students have no face to face interactions rather they communicate with each other through distance modes of learning like correspondence through postal mail, online interaction through video or audio conferencing, electronic mail, radio, television, Internet, cable, broadband lines, fiber optics, satellite, wireless communications devices; or video cassettes, DVDs, and CD-ROMs, etc.

"Distance education is a planned teaching/learning experience in which teacher and students are separated by physical distance. In distance education courses and programs, student-teacher interaction may occur and course materials may be delivered in an asynchronous or synchronous mode over a wide spectrum of existing and evolving media". 
A degree or certificate program is considered distance education when a substantial number of credit hours (fifty percent or more of the courses for the program) will be delivered through distance education. "A course is considered distance education when the majority of instruction is delivered through distance education".

In recent times, courses in distance education are offered in blended way. It means that some courses are offered through traditional face to face instruction where as some courses are offered using any one of more than one modes of distance education like Internet video or audio conferencing, electronic mail, radio, television, Internet, cable, broadband lines, fiber optics, satellite, wireless communications devices; or video cassettes, DVDs, and CD-ROMs, etc. Provision and expansion facilities for vaster population of the country are the need of the hour. For this purpose distance education is the most effective tool in order to provide educational facilities to maximum population in cost effective mean for the country.

\section{OBJECTIVES}

The strategies for quality distance higher education have been developed to achieve following objectives:

$>$ To highlight the concept of distance education in current era;

$>$ To develop strategies for introducing quality distance higher education.

Followings are some suggested strategies for quality based distance higher education programs in universities/institutions:

\section{Mission Statement and Commitment of Institution}

The institutions/ universities initiating distance education (DE) programs must have a clear and written mission statement for the programs they are going to launched. Not merely they have a documented mission statement of $D E$, rather they should be committed to achieve that mission. The programs offered by the university/ institution should reflect their mission statement. Further the mission statement itself should promise the commitment of the university/ the institution to quality education. The Western Interstate Commission for Higher Education (WICHE, 2001) described nine aspects of "commitment". These were: financial commitment, the physical plant, articulation and other policies, technical support, legal compliance, etc.,

\section{Curriculum and Instruction of Distance Education (DE)}

The content and material presented by institutions/ universities for courses of DE should be up to-date. There should be a curriculum review committee comprising qualified experts in the field of curriculum to revise curricula of DE with changing demands of the knowledge, skills, market and society.

Curricula of DE should be designed on individualized instruction, where students must have opportunities to analyze and assess their own progress within their course. 
- One of best practice in DE is to enhance distance learners motivation through relevant learning experiences which are related to their real life situations. Activities and projects of DE course should be designed in such a way that can foster their learning goals as well they are relevant to their life experiences. This method of content presentation can make learning interesting and meaningful for them. The next thing that can motivate DE learners is that they should be make familiar with the goals and expected outcomes of the programs they are going to pursuit.

$>$ Curricula of distance course should be developed to answer questions like: What are the skills and knowledge we have planned to transmit through of correspondence program? Whether our course objectives, methodology, course content and communication method for the suggested course, everything is in alignment with each other?

> Course designing of DE should not be a replication of traditional classroom, rather in terms of maximum enhancement of distance learners' capabilities through medium best suited for that course. Although acquisition of knowledge is essential for distance students but that only acquisition of knowledge is not sufficient for learners in the 21st century. There are important skills that are necessary for living a successful life. There universities/institutions of distance education should design their courses to promote at least following some important life skills:

- Communication skills

- Interpersonal and intrapersonal skills

- Decision-making skills

- Technical skills

- Awareness about environment

- Courage to take challenges and initiative

- Leadership skills

- Problem solving skills

- Think about life matters rationally and reasonably

- Tolerance

- Patriotism to sacrifice for the country

- Scientific outlook towards matters of life

- Use of ICT

\section{Distance Higher Education for Four Pillars}

$>$ Learning to do, to acquire knowledge and skill and the competence to deal with it in many situations.

$>$ Learning to live together, by developing an understanding of other people and an appreciation of interdependence, carrying out joint projects and learning to manage conflicts, in a respect of mutual values, mutual understanding and peace.

Learning to be, so as to better develop one's personality and be able to act with judgment and personal responsibility. 
On the basis of the assumption that adolescents should "learn to be" and to "live together", there is a need for the provision of a more relevant education which moves beyond the acquisition of knowledge and technical / vocational skills.

$>$ Course should be developed by consultation of these experts and then it should be peer review by expertise from senior members and experts of board of governors (BOG) of the concerned institutions/ universities/ university. These members should grant sanction of these courses by measuring them against latest trends and market demands. Feedback about course can be gained through students' feedback on prescribed evaluation form of the course.

$>$ Keeping in view demand of ICT era we need to introduce blended course of distance higher education in order to bring quality in programs like computerinteractive hypertext course where student receive immediate feedback on their assignments and exercises they do in distance education programs. For developing standardized instructional material for e. learning courses, the Pennsylvania State University titled An Emerging Set of Strategies for the Design and Development of Distance Education (IDE, 1998) presented the following five principles of course design:

- Learning goals and content presentation;

- Interactions;

- Assessment and measurement;

- Instructional media and tools; and

- Learner services and support.

\section{Infrastructure and Technology}

$>$ In current information communication and technology (ICT) era we need to run DE programs in blended way. It means to introduce combination of more than one modes of education, e.g. traditional as well as online or electronic learning (e. learning). Therefore, in the world of today no institution can launch online programs of DE until it has an up to-date technology based laboratories with complete infrastructure and personnel which is essential for successful delivery of electronic learning programs.

$>$ In the world of today educational institutions can survive by offering their courses on ground campus as well as online courses. It is the need of the hour to blend courses of distance education. Therefore, for best results it is suggest that in order to make place in the world of work, the universities/institutions should launch courses not only on their ground campuses but through online means as well.

> Universities/institutions should offer programs of distance learning keeping in view the market value and market trends on the basis of demand supply ratio. For this purpose they can conduct survey. 
> Universities/institutions should have sufficient resources and infrastructure; physical, financial and human to continue distance education programs on sustainable basis.

> Universities/institutions offering DE programs should have a national and international network so that they can develop and atmosphere of collaboration and can exchange their practices at national and international level in order to bring quality in their programs and to cater the demands of $21^{\text {st }}$ century.

$>$ The American Federation of Teachers report Distance Education: Strategies for Good Practice posits (2001) recommended close personal interaction between students and teachers of DE. The IHE report (2000) about "Teaching and Learning" in DE further recommended that student interaction with faculty and other students as an essential characteristic that could be facilitated through a variety of technologies including voice mail and/or email.

\section{Promotion of Research Culture in Distance Higher Education Programs}

$>$ The institutions/ universities offering DE programs should be provided opportunities for independent research projects like students of traditional system. For this purpose institutions should facilitate distance learners for having access to electronic research material. For this purpose students should be provided short online training in how to use electronic material like digital libraries for research purposes and how to avoid plagiarism while consulting electronic material.

> Training workshops at regional level and online guidance and supervision can be provided for completion of research projects in distance higher education programs.

$>$ In order to promote research culture and to provide research training to graduates, universities/ institutions can arrange educational conferences and seminar where senior faculty members and guest speakers can train graduates students in the skills of doing research projects.

$>$ In order to develop life skills in distance learners, educational conferences and seminars can be arranged at regional/local level where distance learners should be provided an opportunity to present an article/essay and it should be made mandatory component of the distance course.

\section{Faculty and Technical Support}

$>$ The instructor/teacher works as a human guide in DE courses. Therefore, there is special need for training of faculty involved in DE/E. learning courses. This training should be of a specific type as interaction of teacher- student in DE programs is of a specific nature and demands of this interaction are rather different than interaction between teacher and student in tradition face to face learning in traditional classroom. For this purpose institution planning to launch DE programs will have to provide their faculty members special training for teaching and dealing with DE students.

$>$ Supplementary benefits should be providing to faculty members for their extensive effort in making distance education program successful. 
$>$ The instructors working with distance education must be trained through specific techniques of instruction for teaching students of distance education.

$>$ Competent and experienced senior instructors and evaluators must be are recruited to evaluate performance of distance education instructors.

$>$ Use of library is very important in any system of education. However, in DE it is the most important factor for universities/institutions offering DE programs. DE institutions/universities should make it sure that they have rich resourceful physical as well as digital libraries available for all its students with approach to latest material globally available.

\section{National Accreditation Council for Distance Education (NACDE)}

$>$ National level accreditation councils should be established to grant accreditation / approval of programs run by a university of institution. National accreditation council should develop standards and implement for accreditation of distance education programs for maintaining quality of DE programs and should provide complete strategies for measuring quality of distance learning programs/courses. These standards should be transparent and consistent with the quality framework of Higher Education Commission (HEC) The country. Until national council at does not recognize or accredited a program of $D E$, the concerned university/ institution should not have authority or right to advertise admission in that DE program.

> NACDE should provide accurate information about procedure of assessment according to developed standards of NACDE.

$>$ For bringing quality in distance higher education, institutional mission regarding quality distance higher education courses, and students' support services, faculty support, resources of the institution, curriculum and instruction and students' learning outcomes should be examined on set criteria standards.

$>$ The institutions/universities offering programs of distance higher education but not meeting criteria for quality given by accreditation should be banned and they should be given specific time for up gradation of their programs. If they are unable to fulfill due requirement within given time frame, their registration should be canceled immediately. Different standards/criteria should be set each type of distance education courses, e.g. for correspondence courses and for online courses.

> The quality of the course content, instruction quality, and quality of students' holistic experiences can be measured. Accreditation council should evaluate following major areas of institutions/ universities/ universities offering distance education courses for accreditation of course:

$>$ Mission statement of institution: Whether institution offering distance learning has clear mission statement about promotion and launching of distance education course?

$>$ Organizational Structure of Institution: Does the institution have suitable organizational structure for offering of DE programs of quality- based?

> Institutional Resources and Infrastructure: Does the institution/ university has sustainable financing for continuous provision of quality distance education programs? Does it have sufficient infrastructures like latest technology 
resources, expertise and equipment related to programs of distance education that it is going to offer?

$>$ Curriculum and Instruction: Does the institution have appropriate and quality based curricula for offering quality based distance education programs? Whether curricula are revising regularly in order to incorporate new knowledge and technology or whether stakeholders are involved in revising curricula?

> Faculty Support: Does institution/ university has enough and qualified faculty, and they have enough sources and facilities for dealing with distance education programs?

> Student Support: Whether students are provided counseling services, equipments facilities, and training in use of web- based learning?

> Student Learning Outcomes: Does institution/ university has well defined system to evaluate the quality of distance learning through students' outcomes?

\section{Student Support Services}

> An important aspect of quality DE is concerned with students support services. These services included guidance for admission in various courses, financial support, support during studying of DE courses, easily approach to faculty members, program coordinator. Sometimes it is very difficult for students to make decisions about selection of course for which they have potential. At such moment they need guidance counseling of some senior in experience and qualification. Therefore, it is necessary to institutions/ universities offering DE programs that they must have students' counseling service at the campus at the time of admission. When developing programs of distance education we have to keep in view the context of our diverse distance learners like their cultural backgrounds, knowledge back ground, schooling background, availability of resources of our distance students, especially resources of ICT, the time they will have for the completion of assignments.

$>$ It is a market principle that when we launch some program, product or service, it should fulfill our customers' needs and satisfies them and we have to make sure through continuous evaluation and monitoring that our customers are satisfying with our product or service. This principle of market should be applied towards DE programs. In DE programs our customers are out students. We have to show sensitivity towards of DE students' needs, problems and feelings like tradition students. Distance education faculty and staff should be aware of their students' characteristics, and the social, financial, technical background of their enrolled students. These types of concern towards our clients (students) have positive connection with the success of any program of DE. The expectation about students' performance in distance education programs should be challenging like students of traditional programs. DE students should be provided certain motivation in the various ways of testing.

Students should be provided adequate advertisement about recruitment for admission, admission criteria and requirement for each course of $D E$, counseling about selection of appropriate programs according to their needs, interest and caliber, counseling about delivery of course material attempting of course 
assignments and projects, and if need they should be provided financial assistance and technical support.

$>$ The institutions/ universities offering DE programs should make it sure that they have adequate financial resources and equipment, technical expertise, other related facilities and above all qualified faculty who could plan and design instruction for distance teaching to make it possible to continuously sustain program in future.

\section{Evaluation and Assessment}

$>$ The institution should have a comprehensive assessment system for evaluation of course offered through online or correspondence in order to evaluation the effectiveness of its programs.

> This comprehensive evaluation system should include assessment of students' learning outcomes, number of students admitted in courses and their rate of retention, students' satisfaction about programs offered by the institution/ university, faculty performance evaluation, evaluation of course content.

\section{Monitoring}

It has been observed that students registered in distance education course is not him/herself submitting assignments, rather their assignments are being prepared by some other person who may have got this level of education. It has been observed that sometime some other person is taking examination instead of original candidate. In the age of information communication and technology (ICT) institutions/ universities offering distance higher education courses should introduced latest technology based system that can detect any type of mal practices either in submission of assignments or in taking examination.

$>$ Institutions/universities should introduce and monitor confidential identification and password for enrolled students through identity verification technologies.

\section{Admission Procedure}

$>$ The admission in DE Programs is advertised in national and local newspapers and through internet web browsers. The advertisement describes complete information about entry criteria, course structure, qualifying criteria for award of degree, semester duration, examination rules, fee information, etc.

$>$ The institution/university should made mandatory the administration of an aptitude test for entry into every discipline of DE courses/ programs.

$>$ It is a fact that the purpose of distance education is to expand educational facilities for specific population of students who do not have opportunities to enhance their educational qualification through general education. However, it is essential to achieve quality in distance higher education programs. For this purpose, it is suggested that there should be at least a set standard/criteria for entry in to various distance courses of higher education level.

$>$ Quality Education in Distance Higher Education Programs and Quality Control/Quality Assurance System

$>$ The institutions/universities offering higher education programs through distance means should never compromise on quality of education. They should 
have a particular system of quality assurance in order to check the quality of all aspects of DE programs offering by the institution. This quality assurance system should have specialized personnel in checking the quality of offered programs. The end product should meet the requirements of the stakeholders.

$>$ The universities/institutions delivering distance education programs consult quality assurance agencies in order to make their programs effective according to strategies and quality criteria provided by quality assurance agencies.

$>$ It has been observed that students of DE indulge in unethical practices. Some examples are described here: sometimes assignments are written by another person, it may be relative, friend or some professional who write students assignments on fixed rates and students purchase these sub- standards assignments; likewise sometimes even attending mandatory workshops is taken very lightly and maximum resources are used to get unfair attendances in the workshops.

Sometimes students directly approach respective tutors of their assignments and personally requested them for grant of marks without writing their assignments. They just fill in assignment forms and get marks only on form of assignment without writing any sort of assignment. It happened that if a tutor is found honest or strict, then a next step is adopted and it is to approach assignment tutors indirectly through his/ her friend or relative for the same purpose. Another practice related to distance education is appearance of bogus candidate in place of original candidate in the examination halls.

$>$ Keeping in view this type of situation of distance education programs, it is suggested that there should be introduce code of ethics for students completing online assignments and for appearing in online examination of distance education courses. Likewise there is need to train specifically our faculty members/instructors/tutors engaged in distance education program and we should introduce for them code of ethics for dealing with distance students. So that status of distance education programs may be uplifted.

$>$ The institutions/universities offering online distance higher education courses should establish an expected communication etiquettes criteria and for faculty members and students for online communication online with each other and faculty members and students should adhere that protocol. It is a fact that course designing for e. learning is at the same time, difficult, it require more finance, and expertise as compare to traditional courses. Therefore, institutions/universities offering DE courses must have sufficient finance, resources and expertise available for designing courseware for electronic learning.

$>$ In every institution/university of distance education programs, there should be a team of content matter experts, instructional designers and technology specialists who have expertise in their distinctive area.

> They should design, revise and develop courses of distance education, whether these are courses of on ground or online education. 


\title{
CONCLUSION
}

As a conclusion, tihis study can be summarized on "there is need to introduce quality distance education programs. It can be done through bringing quality in the curriculum and instruction of distance education programs, providing students quality support services, training faculty members in innovative methods of instruction of distance education, provision of technical support for promotion of research culture, adopting multiple ways of assessment of distance students, developing code of ethics for distance education faculty members and students, provision of quality infrastructure and technology, launching courses of distance education only through approval of national accreditation council for distance education (NACDE) and taking measures of check at every delivery system of distance education courses through quality control agencies."

\section{BIODATA and CONTACT ADDRESSES of the AUTHOR}

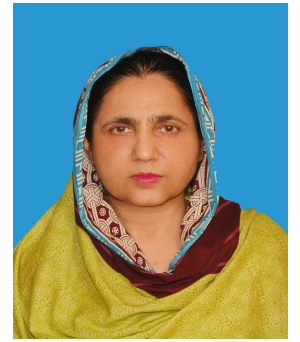

Dr. Sufina Khatoon MALIK is Assistant Professor at Education Department National University of Modern Languages (NUML) Islamabad, Pakistan. She is an experienced teacher and has more than $\mathbf{2 8}$ year experience in the field of educational administration, educational research and teaching. More than 37 research articles have been of Dr. Sufiana Khatoon MALIK is published in national and international journals. In addition, she is author of three books. She has worked a lot for expansion of female education and providing free education opportunities for orphan children in the underdeveloped area of Pakistan (Isa Khel, Mianwali). Her areas of interest are: Curriculum and instruction, Teacher Training and Development, Professionalism, Reflective Practice, Female Education, Teacher Leadership, Students' Learning in Information Communication Technology (ICT) Era.

\author{
Dr. Sufiana Khatoon MALIK \\ Assistant Professor \\ Education Department \\ National University of Modern Languages (NUML), \\ Islamabad, PAKISTAN \\ Email: skhatoon@numl.edu.pk
}

\section{REFERENCES}

American Council on Education. (1996). Guiding principles for distance learning in a learning society. Washington, DC: ACE Central Services.

American Association for Higher Education. (2000). Implementing the Seven Principles: Technology as a Lever. Washington, DC: AAHE

Berge, Z. (2001). Sustaining Distance Training: Integrating Learning Technologies into the Fabric of the Enterprise. San Francisco: Jossey-Bass. 
Eaton, J. (2000). Core Academic Values, Quality, and Regional Accreditation: The challenge of distance learning. Washington, DC: Council for Higher Education Accreditation.

Innovations in Distance Education (1995). An Emerging Set of Guiding Principles and Practices for the Design and Development of Distance Education. University Park, PA: Pennsylvania State University. A Report of the Faculty Initiative Funded by a grant from The AT\&T Foundation to The Pennsylvania State University in collaboration with Lincoln University and Cheyney University.

Sufiana, K. M. (2010). Role of Distance education in the Expansion of Female Higher Education in The country- A Review. Published in Turkish Online Journal of Distance Education-TOJDE January 2010 ISSN 1302-6488 Volume: 11 Number: 4 Article 10

Sara, D. G. (2001). How to be a Successful Online Student. New York: McGraw-Hill J. L

Sufiana, K. M. (2011). Nature of Teacher-Students' Interaction in Electronic Learning and Traditional Courses of Higher Education- A Review. Published in Turkish online Journal of Distance Education-TOJDE October 2011 ISSN 1302-6488 Volume: 12 Number: 4 Article 9 